\title{
Evaluation of prehospital insertion of the laryngeal mask airway by primary care paramedics with only classroom mannequin training
}

\author{
Michael J. Murray, MD; ${ }^{*}$ Marian J. Vermeulen, MHSc; ${ }^{\dagger}$ Laurie J. Morrison, MD, MSc; ${ }^{\dagger \dagger}$ \\ Tim Waite, A-EMCA ${ }^{\S}$
}

\begin{abstract}
Introduction: The laryngeal mask airway (LMA ${ }^{\mathrm{TM}}$ airway) provides adequate ventilation and offers a suitable alternative for airway management in patients with cardiac arrest if primary care paramedics do not have intubation skills or are unable to intubate. Training in the use of the LMA usually occurs in the operating room.

Objective: To describe the use of the LMA by paramedics in prehospital adult non-traumatic cardiac arrest patients after classroom mannequin training. The study took place in a suburban rural emergency medical service.

Methods: This is a 2-phase observational study of the effect of paramedic training for LMA insertion using a mannequin and the success rate in the prehospital setting. All paramedics successfully completed classroom mannequin training. All subsequent prehospital adult non-traumatic cardiac arrest patients from mid-February 1999 to Mar. 31, 2000, were eligible. Subjective assessment of chest expansion, ease of ventilation and auscultation defined adequacy of ventilation. Data collected included the number of insertion attempts, reasons for failure, ease of insertion, adverse events and reasons for not attempting intubation. Statistical analysis comprised descriptive frequencies, chi-squared tests for comparison of categorical variables and analysis of variance for continuous variables.

Results: 208 paramedics (100\%) successfully completed training. The mean number of attempts was 1 , and only $4(2.1 \%)$ paramedics required a second attempt with a mannequin. The paramedics' perception of ease of use comparing the LMA with a bag valve mask (BVM) was evenly distributed across the 3 descriptors: 70 (39\%) scored the LMA as easier to use, $57(31 \%)$ as more difficult, and $54(30 \%)$ stated there would be no difference. Of the 291 arrests during the study period, insertion of the LMA was attempted in $283(97.3 \%)$ and was successful in $199(70 \%)$ patients. The LMA became dislodged in $5(2.5 \%)$ cases and was removed in $12(6 \%)$ to clear vomit from the airway. The overall success rate was $182(64 \%)$. The incidence of regurgitation prior to attempted insertion of the LMA was $28 \%$ (79 patients). Success rates did not vary significantly with the incidence of vomiting prior to insertion $(p=0.11)$. The majority of the paramedics evaluated LMA insertion as Very easy $49 / 220(22.3 \%)$ or Easy $87 / 220(39.6 \%)$. Paramedic evaluation of ease of use varied with success $(p=0.001)$.
\end{abstract}

\footnotetext{
*Medical Director and §Program Director, Base Hospital Program, Department of Emergency Services, Royal Victoria Hospital, Barrie, Ont. tDivision of Prehospital Care, Department of Emergency Services, Sunnybrook and Women's College Health Sciences Centre; Department of Health Administration, University of Toronto, Toronto, Ont.

‡Division of Emergency Medicine, Department of Medicine, University of Toronto, and Toronto Emergency Medical Services, Toronto, Ont.

Presented at the Canadian Association of Emergency Physicians Annual Scientific Meeting, Hamilton, Ont., Apr. 18-20, 2002.
}

Received: Nov. 19, 2001; final submission: June 5, 2002; accepted: June 15, 2002

This article has been peer reviewed. 
Conclusions: This study reports a $100 \%$ training success rate with a mannequin and a $64 \%$ success with LMA insertion and ventilation in the field by paramedics among adult out-of-hospital nontraumatic cardiac arrest patients.

Key words: emergency medical services, airway, education, cardiac arrest

\section{RÉSUMÉ}

Introduction : Le Laryngeal Mask Airway ${ }^{\mathrm{MD}}$ (LMA) (masque laryngé) offre une ventilation adéquate ainsi qu'une solution de rechange appropriée lors de la prise en charge des voies aériennes de patients en arrêt cardiaque si les ambulanciers paramédicaux de soins immédiats (APSI) ne possèdent pas les habiletés d'intubation ou sont incapables d'intuber. La formation à I'utilisation du LMA s'effectue en salle d'opération.

Objectif : Décrire I'utilisation du LMA par les APSI chez des patients adultes en arrêt cardiaque non traumatique à la suite d'une formation en classe sur des mannequins. L'étude eut lieu dans un service d'urgence en milieu rural.

Méthodes : Il s'agissait d'une étude d'observation en deux étapes sur l'effet de la formation à l'insertion du LMA sur un mannequin et le taux de succès en milieu préhospitalier. Tous les APSI complétèrent avec succès la formation en classe sur des mannequins. Tous les patients adultes victimes d'arrêts cardiaques non traumatiques subséquents reçus entre la mi-février 1999 et le 31 mars 2000, étaient admissibles à l'étude. Une évaluation subjective de l'expansion thoracique, de la facilité de la ventilation et d'auscultation constituait le critère de définition de la réussite de la ventilation. Les données recueillies comprenaient le nombre de tentatives d'insertion, les raisons de l'échec des tentatives, la facilité d'insertion, les résultats négatifs et les raisons de ne pas tenter l'intubation. L'analyse statistique était constituée des fréquences descriptives, des tests $\mathrm{Chi}^{2}$ pour comparaison des variables catégorielles et de l'analyse de variance pour les variables continues.

Résultats : Deux cent huit APSI (100 \%) complétèrent la formation avec succès. Le nombre moyen de tentatives était de 1 et seulement 4 APSI $(2,1 \%)$ durent effectuer une seconde tentative sur un mannequin. La perception des APSI de la facilité d'utilisation comparativement au masque laryngé avec sac-valve-masque était répartie également entre les trois descripteurs : 70 (39\%) d'entre eux jugèrent que le LMA était le plus facile à utiliser, 57 (31\%) qu'il était le plus difficile à utiliser et 54 (30\%) ne virent aucune différence. Parmi les 291 arrêts au cours de la période d'étude, l'insertion d'un LMA fut tentée chez $283(97,3 \%)$ d'entre eux et réussie chez 199 patients $(70 \%)$. Le LMA se délogea dans cinq cas $(2,5 \%)$ et fut retiré dans 12 cas $(6 \%)$ pour dégager les voies aériennes des vomissements. Le taux de succès global était de $182(64 \%)$. L'incidence de régurgitation avant la tentative d'installation du LMA était de $28 \%$ (79 patients). Les taux de succès ne variaient pas de façon significative avec l'incidence de vomissements avant l'inertion $(p=0,11)$. La majorité des APSI évaluèrent l'insertion comme étant Très facile : 49/220 (22,3\%) ou Facile : 87/220 (39,6\%). L'évaluation par les APSI de la facilité d'utilisation variait selon le taux de succès $(p=0,001)$.

Conclusions : La présente étude indique un taux de succès de la formation de $100 \%$ sur un mannequin et un taux de succès de $64 \%$ avec l'insertion du LMA et la ventilation sur les lieux de l'incident par des APSI chez des patients adultes victimes d'arrêts cardiaques non traumatiques en situation préhospitalière.

\section{Introduction}

The laryngeal mask airway (LMA ${ }^{\mathrm{TM}}$ airway; LMA North America, San Diego, Calif.) was invented in 1981 by AIJ Brain, an anesthetist, was introduced commercially to some European markets in 1988 and approved for use in the United States in the early 1990s. It is estimated that it has been used on over 15 million patients. ${ }^{1}$ Endotracheal (ET) intubation is the gold standard for airway management and ventilation in cardiac arrest. ${ }^{2,3}$ The LMA offers a satisfactory alternative for airway management in cardiac arrest for prehospital providers lacking advanced airway training. 2,4-8
The LMA is a soft rubber shaft of 5.25 to $12 \mathrm{~mm}$ diameter connected to an inflatable elliptical shaped device that resembles a small version of a facemask. This elliptical end of the device, when properly inserted, sits in the laryngeal inlet up against the esophageal sphincter. The epiglottis is usually free floating within the mask and does not obstruct air flow. When inflated, the mask fills the pyriform fossa on either side and abuts the tongue, pushing the tongue forward. The LMA has been demonstrated to provide adequate ventilation, it requires little time for insertion and runs a low risk of regurgitation..$^{4-8}$

Prehospital provider performance subsequent to various 
training methods for LMA insertion has not been prospectively evaluated. Training options include didactic, mannequin and practical application in the operating room (OR). Operating room time is a premium resource, with paramedic training competing with other medical teaching programs for exposure to controlled airway education in live subjects. Time required for adequate OR exposure to achieve competence may be prolonged, increasing the cost of initial certification and maintenance of competence programs. Mannequin training provides greater flexibility of training and recertification at a much lower cost.

This observational study was designed to describe the use of the LMA in prehospital adult non-traumatic cardiac arrest patients by primary care paramedics (PCPs) following classroom mannequin training. Specifically, we set out to examine intubation success rate, frequency of attempt, as well as the comfort level of the paramedic (in the classroom and in the field) and the receiving physician with the device.

\section{Methods}

\section{Setting}

The study took place in a suburban rural emergency medical services (EMS) system (75000 emergency calls per year) that serves 8 community emergency departments (EDs). At the time of the study, 209 paramedics were trained to the level of a primary care paramedic (PCP or EMT-D), and it is the paramedics with this level of training that we refer to in this study. In addition to semi-automatic defibrillation, PCPs are able to administer subcutaneous nitroglycerin, nebulized ventolin, subcutaneous epinephrine, sublingual nitroglycerin and intramuscular glucagon.

\section{Design}

This was an observational study conducted in 2 phases. Phase one involved the training of paramedics in the use of the LMA using mannequins and the evaluation of paramedic ease of use when compared to bag valve mask (BVM). Phase two was set up to describe the in-field success, complication rate and user evaluation of the device.

\section{Training evaluation phase}

Pre-course preparation comprised a 2-hour self-preparation module and training video followed by 4 hours of didactic teaching and classroom practice on an ALS Trainer ${ }^{\mathrm{TM}}$ mannequin (Laerdal Medical Corporation, Wappingers Falls, NY; www.laerdal.com). Routine recertification of paramedics began in mid-September 1999 and concluded in mid-November 1999, 9 months after the initiation of the study.

\section{Field evaluation phase}

All adult non-traumatic cardiac arrest patients who were treated in the field and then transported to hospital by paramedics from mid-February 1999 to Mar. 31, 2000, were eligible for inclusion in the study. Paramedics responding to a cardiac arrest call initiated the protocols for cardiac arrest management. The second crew member inserted the LMA during the first minute of cardiopulmonary resuscitation if initial shock analysis and defibrillation were unsuccessful. The paramedics reverted to an oral airway and BVM if at any time complications were encountered with ventilation. On arrival of the patient at the ED, the receiving physician assessed the adequacy of ventilation and either continued ventilation with the LMA or replaced it with an ET tube.

\section{Outcome measures}

In phase one, a paramedic's success with LMA insertion was defined as correct LMA placement on 2 occasions and a passing mark $(>80 \%)$ by the paramedic on the written examination. The time to correct insertion of the LMA in the mannequin was recorded. The paramedics scored their comfort with use of the device on a 5-point Likert scale from "Very easy" to "Very difficult," with "Neither" as the mid-point of the scale.

In phase two, successful LMA insertion was defined by adequate ventilation and confirmation of placement. The adequacy of ventilation was determined by the paramedic at the scene and by the emergency physician or respiratory therapist on arrival in the ED. Subjective assessment of chest expansion, ease of ventilation and auscultation defined adequacy of ventilation. The number of insertion attempts, reasons for failure, ease of insertion, adverse events and reasons for not attempting intubation were recorded. The emergency physicians were surveyed using a nonvalidated instrument. They scored the ease of ventilation and acceptability of the insertion of the LMA based on a 3-point Likert scale (i.e., Acceptable, Not acceptable and Very acceptable).

\section{Analysis}

Data were captured on the ambulance call report, and the evaluation form was completed after each LMA use. The data were abstracted by an EMS data entry clerk and entered into a Microsoft Access database. Descriptive statistics (frequencies and means) were calculated for the number of insertion attempts and success rates. Statistical analysis comprised chi-squared analysis for comparison of categorical variables. Analysis of variance was used to compare success rates according to the number of opportunities for attempted LMA insertion among individual para- 
medics. To determine whether success rates changed following recertification, the time period from mid-February to recertification was compared with the period that followed recertification, through to the conclusion of the study on Mar. 31, 2000.

The Emergency Health Services Branch of the Ministry of Health and Long Term Care and the Medical Advisory Committee of the Provincial Base Hospital Advisory Group approved the study.

\section{Results}

\section{Training evaluation phase}

Two hundred and eight paramedics successfully completed training. Of the 193 paramedics in which number of attempts and time to insertion was recorded, the mean number of attempts was 1 , and only $4(2.1 \%)$ paramedics required a second attempt. The mean time to insertion was 19.1 seconds (standard deviation [SD], 5.7 seconds) with a

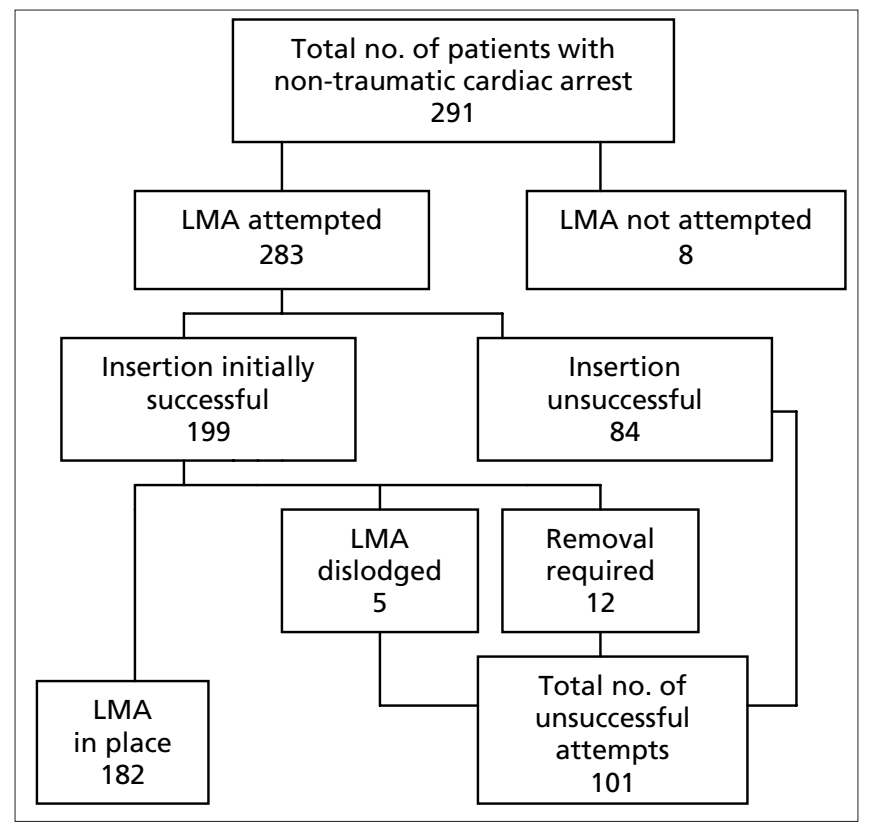

Fig. 1. Insertion of laryngeal mask airway (LMA) among patients with cardiac arrest range of 8 to 40 seconds. In the evaluation, 70 (39\%) paramedics believed the LMA would be easier to use than an oral airway and BVM, 57 (31\%) felt it would be more difficult and 54 (30\%) stated there would be no difference.

\section{Field evaluation phase}

A total of 291 non-traumatic cardiac arrests occurred during the study period. Insertion of the LMA was attempted in $283(97.3 \%)$ of these cases. Among the 8 (2.7\%) remaining patients, reasons for not attempting insertion were provided for 5 patients. Two patients achieved a return of spontaneous circulation after initial defibrillation. In a third, paramedics were unable to open the patient's jaw for insertion. A decision was made to use an oral airway and BVM for another patient who became VSA (vital signs absent) during transport. There was also one instance in which the paramedic was unable to inflate the LMA during preparation of the device.

Paramedics were able to insert the LMA after one or more attempts in 199 (70\%) patients. The LMA became dislodged in $5(2.5 \%)$ cases, and 12 patients $(6.0 \%)$ required its removal due to inability to clear vomit in the airway. The number of successful insertions as defined by the outcome criteria was $182(64.3 \%$; 95\% confidence interval: $58.4 \%, 69.9 \%$ ) (Fig. 1).

Among the 283 attempted insertions, the number of attempts ranged from 1 to 3 and the mean was 1.45 ( $\mathrm{SD}=$ 0.61 ). The distribution of number of attempts, success rate at each attempt and cumulative success rates are shown in Table 1 . The success rate did not change following recertification (before: 128/199 [64.3\%]; after: 54/84 [64.3\%]).

Data on paramedic identification number were available for 281 cases. The number of opportunities for LMA insertion among individual paramedics ranged from 1 to 6 (Table 2). The majority of paramedics had 1 (165 [59\%]) or $2(66[25 \%])$ patient encounters to attempt LMA insertion. The frequency of success did not vary according to experience with insertion of the LMA ( $p=$ $0.76)$. The incidence of regurgitation prior to attempted insertion of the LMA was $28 \%$ (79 patients). Success

\begin{tabular}{|c|c|c|c|}
\hline Attempts & $\begin{array}{l}\text { Insertion attempted, } \\
\text { no. (and \%) }\end{array}$ & $\begin{array}{c}\text { Insertion successful, } \\
\text { no. (and \%) }\end{array}$ & $\begin{array}{l}\text { Cumulative } \\
\% \text { of total }\end{array}$ \\
\hline 1st & $173(61.1)$ & $144(83.2)$ & 50.9 \\
\hline 2nd & 93 (32.9) & $34(34.0)$ & 62.9 \\
\hline $3 r d$ & $17(6.0)$ & $4(23.5)$ & 64.3 \\
\hline Total & $283(100.0)$ & $182(64.3)$ & 64.3 \\
\hline
\end{tabular}


rates did not vary significantly with the incidence of vomiting prior to insertion $(p=0.11)$.

For the 283 attempted insertions, 220 (78\%) questionnaires were completed. Table 3 shows paramedic assessment of the ease of LMA use, which varied according to whether insertion was successful $(p=0.001)$. Paramedics were more likely to rate insertion as Easy or Very easy among successful insertions (118 [65\%]) than in those that were unsuccessful (18 [46\%]).

Questionnaires were distributed to the attending emergency physicians only for the cases in which ventilation by the paramedic had been successful (i.e., 182 cases). Of the 182 questionnaires distributed to these physicians, 126 were completed. Ventilation was rated on a 5-point Likert scale as Easy or Very easy in 94 (75\%) cases and Difficult or Very difficult in $12(9.5 \%)$ cases. The acceptability of the LMA for prehospital airway management in cardiac arrest was described using a 3-point Likert scale; 78 (62\%) were rated as Very acceptable, 35 (28\%) as Acceptable and $13(10 \%)$ as Unacceptable.

\section{Discussion}

This study described a high classroom success rate for paramedics in LMA insertion training using mannequins that translated to a moderate success rate in the field and

\begin{tabular}{|c|c|c|}
\hline $\begin{array}{l}\text { No. of } \\
\text { experiences }\end{array}$ & $\begin{array}{c}\text { Attempts, } \\
\text { no. (and \%) }\end{array}$ & $\begin{array}{c}\text { Successes, } \\
\text { no. (and \%) }\end{array}$ \\
\hline 1 & $165(58.7)$ & $101(61.2)$ \\
\hline 2 & 66 (23.5) & 47 (71.2) \\
\hline 3 & $28(10.0)$ & $18(64.3)$ \\
\hline 4 & $15(5.3)$ & $10(66.7)$ \\
\hline 5 & $6(2.1)$ & $4(66.7)$ \\
\hline 6 & $1(0.4)$ & $1(100.00)$ \\
\hline Total* & $281(100.0)$ & $181(64.4)$ \\
\hline
\end{tabular}

reasonable acceptability and adequacy of ventilation when judged by the paramedics and emergency physicians. If LMA insertion was to be successful only a single attempt was usually required. Regurgitation prior to attempting insertion occurred in a substantial number of patients but did not preclude success. LMA removal due to loss of correct placement or inability to clear the airway occurred in $8.5 \%$ of cases.

This study was designed to assess the success rate of LMA insertion by paramedics in prehospital non-traumatic cardiac arrest adult patients after classroom mannequin training. The training program provided the paramedics with sufficient information and opportunity to achieve $100 \%$ success rate of rapid LMA insertion in mannequins. The success rate in this study was comparable to that observed in 2 other studies. ${ }^{9,10}$ LMA field success rates were unchanged after recertification.

The success rate in the field was lower than in other prehospital studies. ${ }^{7.8}$ One retrospective review reported a successful insertion and ventilation rate of $71.5 \%{ }^{8}$ The majority of paramedics in that study received mannequin training; less than one-third received OR training. Another study compared LMA insertion with Combitube ${ }^{\circledR}$ (Kendall Company, Tyco Healthcare, Mansfield, Mass.) and the Pharyngeal-tracheal Lumen $\left(\mathrm{PtL}^{\circledR}\right)$ Airway (Gettig Pharmaceutical Instrument Company, Spring Mills, Pa.) among paramedics and respiratory therapists trained on mannequins or in the OR. The success rates for insertions were $86 \%$ with the Combitube, $82 \%$ using the PtL, and $73 \%$ using the LMA. There were no significant differences in ventilatory effectiveness with respect to arterial blood gas and spirometry in the ED. There was a trend toward a higher success rate in the group with OR training (80\%) compared with those who had mannequin training $(69 \%){ }^{8}$ Other studies of ET intubation and Combitube indicate that success is greater with OR practise. ${ }^{11,12}$ A study by Alexander and colleagues demonstrated that nonphysician emergency personnel were better able to ventilate with the LMA than with an oral airway and face mask (87\% vs.

Table 3. Paramedic evaluation of ease of insertion

\begin{tabular}{lccc} 
Evaluation & $\begin{array}{c}\text { Insertion successful, } \\
\text { no. (and \%) }\end{array}$ & $\begin{array}{c}\text { Insertion unsuccessful, } \\
\text { no. (and \%) }\end{array}$ & Total \\
\hline Very easy & $47(26.0)$ & $2(5.1)$ & $49(22.3)$ \\
Easy & $71(39.2)$ & $16(41.0)$ & $87(39.6)$ \\
Neither & $31(17.1)$ & $6(15.4)$ & $37(16.8)$ \\
Difficult & $14(7.7)$ & $11(28.2)$ & $25(11.4)$ \\
Very difficult & $18(9.9)$ & $4(10.3)$ & $22(10.0)$ \\
\hline \multicolumn{4}{l}{ Total* } \\
\hline
\end{tabular}


$43 \%$ ) in the OR, with no significant difference in the average insertion time. ${ }^{6}$

In our study, paramedics achieved field LMA intubation with an average of 1.45 attempts. A prospective study comparing the LMA with ET tube placement by experienced paramedics and respiratory therapists observed an average of 1 attempt for LMA insertion and 2.2 for the ET tube. ${ }^{5} \mathrm{~A}$ multicentre study that evaluated LMA insertion by nurses during cardiopulmonary resuscitation reported a $71 \%$ success rate on the first attempt and $26 \%$ on the second. ${ }^{4}$

During phase one, paramedics felt the ease of use of the LMA compared with the BVM. In phase two, the majority of paramedics described LMA use as Easy or Very easy. Not surprisingly, paramedics who had unsuccessful insertions found the device more difficult to use. The literature suggests significant ease of use on anesthetized patients with the LMA compared to the ET tube insertion. ${ }^{5}$ Paramedics rated ease of LMA insertion lower than for BVM, Combitube or PtL Airway. ${ }^{\text {. }}$

A limited sample of physicians completed the evaluation of LMA use. In most cases, the physicians rated the LMA as Easy or Very easy to use and considered it a Very acceptable method of ventilation.

\section{Limitations}

This study was observational. In addition, the outcome measures were not validated. Adequacy of ventilation was subjectively evaluated by the receiving physicians, and there was no attempt to standardize this measure. Incomplete data among both paramedics and physicians also limited the analysis. As a result, we had insufficient information to report adverse events such as regurgitation and time to insertion in the field. This study did not follow survival outcomes nor compare the LMA to other airway adjuncts, as recently reported with pediatric cardiac arrest. ${ }^{13}$

\section{Conclusions}

This study found a 64\% success with LMA insertion and ventilation in prehospital adult non-traumatic cardiac arrest patients attended by paramedics who had been trained using a mannequin model. Paramedics reported ease of LMA use in $61.9 \%$ of cases in the field. More favourable support for ease of LMA use was observed in cases when insertion was successful. Regurgitation prior to attempting LMA insertion was reported in $28 \%$ of cases. Further research should prospectively evaluate LMA training and compare OR training with classroom mannequin training using standardized outcomes for field verification. There is need for a study comparing training models using objective end- points such as tube placement confirmation, survival, adverse event rates and ease of use for LMA insertion with other airway adjuncts, including BVM and oral airway.

\section{Competing interests: None declared.}

Acknowledgements: We thank the paramedics of the region of Simcoe County and Muskoka, Ont., and Lynne Fell RVH Base Hospital, who provided administrative support.

The Emergency Health Services Branch of the Ontario Ministry of Health and Long Term Care funded the study.

\section{References}

1. Baskett PJF. The laryngeal mask in resuscitation [editorial]. Resuscitation 1994;28:93-5.

2. Davies PRF, Tighe SQM, Greenslade GL, Evans GH. Laryngeal mask airway and tracheal tube insertion by unskilled personnel. Lancet 1990;336:977-9.

3. Lawes EG, Baskett PJF. Pulmonary aspirations during unsuccessful cardiopulmonary resuscitation. Intensive Care Medicine 1987; 13:379-82.

4. The use of the laryngeal mask airway by nurses during cardiopulmonary resuscitation. Results of a multicentre trial. Anaesthesia 1994;49:3-7.

5. Reinhart DJ, Simmons G. Comparison of the placement of the laryngeal mask airway with endotracheal tube by paramedics and respiratory therapists. Ann Emerg Med s1994;24:260-3.

6. Alexander R, Hodgson P, Lomax D, Bullen C. A comparison of the laryngeal mask airway and Guedel airway, bag and facemask for manual ventilation following formal training. Anaesthesia 1993;48(3):231-4.

7. Rumball CJ, MacDonald D. The PTL, Combitube, laryngeal mask, and oral airway: a randomized prehospital comparative study of ventilatory device effectiveness and cost effectiveness in 470 cases of cardiorespiratory arrest. Prehosp Emerg Care 1997;1(1):1-10.

8. Tanigawa K, Shigematsu A. Choice of airway devices for 12,020 cases of nontraumatic cardiac arrest in Japan. Prehosp Emerg Care 1998;2:96-100.

9. Dickinson M, Curry P. Training for the use of the laryngeal mask in emergency and resuscitation situations. Resuscitation 1994;28:111-3.

10. Larmon B, Schriger DL, Snelling R, Morgan MT. Results of a 4-hour endotracheal intubation class for EMT-basics. Ann Emerg Med 1998;31(2):224-7.

11. Stratton SJ, Kane G, Gunter CS, Wheeler C, Ableson-Ward C, Reich E, et al. Prospective study of manikin-only versus manikin and human subject endotracheal intubation training of paramedics. Ann Emerg Med 1991;20:1314-8.

12. Stewart RD, Paris PM, Pelton GH, Garretson D. Effect of varied training techniques on field endotracheal intubation success rates. Ann Emerg Med 1984;13(11):1032-6.

13. Gausche MRJ, Lewis SJ, Stratton BE, Haynes CS, Gunter SM, Goodrich PD, et al. Effect of out-of-hospital pediatric endotracheal intubation on survival and neurological outcome: a controlled clinical trial. JAMA 2000;283:783-90.

Correspondence to: Dr. Michael J. Murray, Royal Victoria Hospital, Base Hospital Program, c/o Paramedic Services, Drury House, 60 Wellington St. W, Barrie ON L4N 1K4; MurrayM@rvh.on.ca 